\title{
Association between HLA-A and -B polymorphisms and susceptibility to Henoch-Schönlein purpura in Han and Mongolian children from Inner Mongolia
}

\author{
S.M. Ren ${ }^{1}$, G.L. Yang ${ }^{1}$, C.Z. Liu ${ }^{1}$, C.X. Zhang ${ }^{1}$, Q.H. Shou ${ }^{1}$, S.F. Yu ${ }^{1}$, \\ W.C. $\mathrm{Li}^{1}$ and X.L. Su${ }^{2}$ \\ ${ }^{1}$ Department of Pediatrics, Affiliated Hospital, \\ Inner Mongolia Medical College, Hohhot, Inner Mongolia, China \\ ${ }^{2}$ Clinical Research Center, Affiliated Hospital, \\ Inner Mongolia Medical College, Hohhot, Inner Mongolia, China \\ Corresponding author: X.L. Su \\ E-mail: xlsu@hotmail.com
}

Genet. Mol. Res. 11 (1): 221-228 (2012)

Received March 14, 2011

Accepted November 29, 2011

Published February 3, 2012

DOI http://dx.doi.org/10.4238/2012.February.3.2

\begin{abstract}
We examined a possible association between HLA-A and -B polymorphisms and susceptibility to Henoch-Schönlein purpura(HSP) in Han and Mongolian children in Inner Mongolia, through a case-control study. Two hundred and sixty-eight unrelated children were enrolled, including 56 Mongolian and 50 Han children with HSP, 66 healthy Mongolian and 96 healthy Han children as a control group. HLA-A and -B alleles were indentified by PCR-sequence-specific oligonucleotide analysis and were further analyzed by PCR-sequencing-based typing (SBT). Frequencies of HLA-A*11, HLA-B*15 in Mongolian patients and HLA-A*26, HLA-B*35, HLA-B*52 in Han patients were higher than those in the corresponding control group $(\mathrm{P}<0.05)$, while frequencies of HLA-B*07 and -B*40 in Mongolian HSP patients were lower than those in the control group $(\mathrm{P}<0.05)$. Further analysis using PCR-SBT showed that all HLA-A*11 were HLA-A*1101, and most HLA-B*15 were HLA-B*1501 in Mongolian HSP patients. All HLA-A*26 were
\end{abstract}


HLA-A*2601 and HLA-B*35 were mostly HLA-B*3503 in Han patients. There were more Han patients with severe manifestations than Mongolian patients $(\mathrm{P}<0.05)$. Frequencies of HLA-A*26, HLA-B*35 and HLA-B*52 in Han patients were higher than in Mongolian patients $(\mathrm{P}<0.05)$. We conclude that HLA-A*11(*1101) and -B*15(*1501) are associated with susceptibility to HSP in Mongolian children and HLA-A*26(*2601), HLA-B*35(*3503) and HLA-B*52 are associated with susceptibility to HSP in Han children. HLA-B*07 and $-B^{*} 40$ may be protective genes in Mongolian children. The different frequencies of HLA-A and -B in Mongolian and Han children may be responsible for the different manifestations in these two ethnic groups.

Key words: Henoch-Schonlein purpura; Children; Mongolian; Han; HLA-A; HLA-B

\section{INTRODUCTION}

Human leukocyte antigens (HLA) are encoded by genes located in the major histocompatibility complex region on the short arm of human chromosome 6p21.3 (Volz et al., 1994). HLA genes show the highest level of allelic polymorphism of all known human genes. The polymorphisms of HLA in the Chinese population were thoroughly studied in the early 1980s (Sun et al., 1984). The result showed that the distribution of Chinese HLA could be divided into North and South groups according to genetic distance values and the differences of HLA alleles among different ethnic groups in one region, which were smaller than in the same ethnic group from different regions. Recently, Shen et al. (2008) studied the HLA-A, -B, and DRB1 in a Mongolian population and found that there were more HLA alleles in this ethnic group compared with data from previous studies (Yan et al., 2002; Xu et al., 2004; Zhang et al., 2005). Recently, more and more studies have focused on the correlation between HLA alleles and immunologic disease (Yang et al., 2007; Soylemezoglu et al., 2008b). HLA-B*58 was found to be a susceptibility gene for purpuric nephritis (Amoli et al., 2002); major histocompatibility complex class I chain-related gene A was studied to associate it with Behcet disease (Hughes et al., 2005); HLA-DQB1*0301 was found to be a susceptibility gene for Henoch-Schönlein purpura (HSP) in a Han population from northern China (Fan et al., 2006).

HSP is a hereditary inflammatory disease that affects skin, joint, gastrointestinal tract, and kidney. The patients usually show purpura on limbs and have joint pain, gastrointestinal bleeding and purpuric nephritis (Kawasaki et al., 2006; Ozen et al., 2006; Shin et al., 2006). A study showed that HLA-DRB*11,*14 and *18 were considered to be susceptibility genes for HSP in children (Liu et al., 2008; Soylemezoglu et al., 2008a). Previously, our research group found that the frequency of HLA-DRB1 between Mongolian and Han children with HSP was different by polymerase chain reaction (PCR) sequence-specific primers, which probably caused more severe manifestations in Han children with HSP (Ren et al., 2003). However, there was no research on the polymorphism of HLA-I and HSP in Mongolian and Han children, In the present study, PCR-sequence-specific oligonucleotide (PCR-SSO) was performed to study the HLA-I (A, B) alleles of Mongolian and Han children with HSP, followed by PCRsequencing-based typing (PCR-SBT) to identify susceptible loci with high resolution. 


\section{MATERIAL AND METHODS}

\section{Subjects}

A case-control study was performed. A total of 56 unrelated Mongolian (34 males and 22 females, with an age range between 2 and 14 years) and 50 Han children ( 25 males and 25 females, with an age range between 3 and 16 years) with HSP hospitalized in our hospital, Inner Mongolia Hospital, Chinese and Mongolian Hospital and Xilin Gol League Hospital, from September 2000 to December 2005 were enrolled; 66 unrelated healthy Mongolian children and 96 healthy Han children were randomly selected as the control group. Every subject was from a family who has been living in Inner Mongolia for three generations with no history of mixed marriages or other immune diseases. When the Hardy-Weinberg equilibrium was evaluated, we found that the HLA-A and -B distribution was in accordance with Hardy-Weinberg expectations $(\mathrm{P}>0.05)$. All subjects gave informed consent. Our experiment was approved by the Inner Mongolia Medical College Affiliated Hospital Ethics Committee.

The diagnoses of HSP and diagnostic criteria of organ damage were based on the new validated criteria for HSP diagnosis published by the European League Against Rheumatism and Pediatric Rheumatology Society: "A patient was classified as HSP in the presence of purpura or petechiae (mandatory) with lower limb predominance plus one of four criteria: 1) abdominal pain; 2) histopathology (IgA); 3) arthritis or arthralgia, or 4) renal involvement". Purpura caused by other factors like thrombocytopenia, rheumatic arthritis, primary nephritis, and acute abdomen were excluded. Damage in joints, stomach, intestine and kidney were included in organ damage besides purpura on skin.

\section{PCR-SSO}

DNA was isolated from venous blood and amplified according to instructions provided by the manufacturer (Dynal-RELI, Norway). PCR products went through denaturalized hybridization, membrane wash and staining. Results were analyzed by the PMP analysis system.

\section{PCR-SBT}

DNA from samples with HLA susceptible loci detected by PCR-SSO was amplified and purified to prepare for sequencing as described elsewhere (Flomenberg et al., 2004). Results of sequencing were analyzed by the Match Tools PPC and MT Navigator software (PE Company) and the unknown sequencing results were analyzed in the data bases A23 L23 and B23 L397.

\section{Statistical analysis}

Statistical analysis was performed by SPSS 12.0. Data are reported as means \pm SD. Gene frequencies were calculated by direct counting; gene frequencies and incidence of manifestations were compared between groups by the $\chi^{2}$ test or the Fisher exact test. Comparison of gene frequencies was based on univariate analysis, alleles with $\mathrm{P} \leq 0.2$ were further analyzed by multivariate logistic regression, and odds ratio (OR) and $95 \%$ confidence interval (CI) were calculated. Etiologic fraction (EF) and prevention fraction (PF) were also calculated. 


\section{RESULTS}

\section{Distribution of HLA-A and -B alleles in Mongolian and Han children with and without HSP}

Fourteen alleles of HLA-A and 21 alleles of HLA- B were tested in Mongolian children. We found that gene frequencies of HLA-A*11 and HLA-B* 15 were 16.1 and $26.8 \%$ in patients, which were much higher than the 9.1 and $10.6 \%$ found in the control group $(\mathrm{P}=0.047$, $\mathrm{OR}=2.325,95 \% \mathrm{CI}=1.012-5.340, \mathrm{EF}=0.342 ; \mathrm{P}=0.002, \mathrm{OR}=3.341,95 \% \mathrm{CI}=1.561-7.148$, $\mathrm{EF}=0.478$, respectively; Table 1), indicating that HLA-A*11 and HLA-B*15 were susceptible to HSP; whereas gene frequencies of HLA-B*07 and HLA-B*40 in patients were 1.8 and $7.1 \%$, respectively, which were much lower than the 12.1 and $16.7 \%$ found in the control group $(\mathrm{P}=$ $0.007, \mathrm{OR}=0.188,95 \% \mathrm{CI}=0.225-0.560, \mathrm{PF}=0.454 ; \mathrm{P}=0.005, \mathrm{OR}=0.259,95 \% \mathrm{CI}=0.101$ $0.666, \mathrm{PF}=0.433$, respectively; Table 1 ), indicating that HLA-B $* 07$ and HLA-B $* 40$ may have a protective function in HSP. There was no statistical significance between other alleles.

\begin{tabular}{|c|c|c|c|c|c|c|c|c|c|c|c|}
\hline \multirow{3}{*}{$\begin{array}{l}\text { HLA-A, } \\
\text {-B alleles }\end{array}$} & \multicolumn{4}{|c|}{ Univariate analysis } & \multirow[t]{3}{*}{$\chi^{2}$} & \multirow[t]{3}{*}{$\mathrm{P}$} & \multicolumn{5}{|c|}{ Multivariate logistic regression } \\
\hline & \multicolumn{2}{|c|}{ Patients $(\mathrm{N}=112)$} & \multicolumn{2}{|c|}{ Control $(\mathrm{N}=132)$} & & & \multirow[t]{2}{*}{ B } & \multirow[t]{2}{*}{ Wald } & \multirow[t]{2}{*}{$\mathrm{P}$} & \multirow[t]{2}{*}{ OR } & \multirow[t]{2}{*}{$95 \% \mathrm{CI}$} \\
\hline & No. & Frequency & No. & Frequency & & & & & & & \\
\hline HLA-A*01 & 12 & 0.107 & 8 & 0.061 & 1.744 & 0.187 & 0.844 & 2.854 & 0.091 & 2.325 & $0.874-6.188$ \\
\hline $\mathrm{A} * 02$ & 26 & 0.232 & 36 & 0.273 & 0.527 & 0.468 & & & & & \\
\hline$A * 03$ & 2 & 0.018 & 5 & 0.038 & - & 0.458 & & & & & \\
\hline$A * 11$ & 18 & 0.161 & 12 & 0.091 & 2.738 & 0.098 & 0.844 & 3.954 & 0.047 & 2.325 & $1.012-5.340$ \\
\hline $\mathrm{A} * 24$ & 24 & 0.214 & 38 & 0.288 & 1.731 & 0.188 & 0.090 & 0.072 & 0.788 & 1.094 & $0.567-2.109$ \\
\hline$A * 26$ & 0 & 0.000 & 6 & 0.045 & - & 0.032 & -6.824 & 0.208 & 0.648 & 0.001 & $0.000-5.934 \mathrm{E}+09$ \\
\hline$A * 29$ & 1 & 0.009 & 1 & 0.008 & - & 1.000 & & & & & \\
\hline$A * 31$ & 5 & 0.045 & 7 & 0.053 & 0.091 & 0.763 & & & & & \\
\hline$A * 32$ & 6 & 0.054 & 2 & 0.015 & - & 0.148 & 1.537 & 3.337 & 0.068 & 4.650 & $0.894-24.187$ \\
\hline$A * 33$ & 12 & 0.107 & 8 & 0.061 & 1.744 & 0.187 & 0.844 & 2.854 & 0.091 & 2.325 & $0.874-6.188$ \\
\hline$A * 34$ & 0 & 0.000 & 2 & 0.015 & - & 0.501 & & & & & \\
\hline$A * 66$ & 1 & 0.009 & 0 & 0.000 & - & 0.459 & & & & & \\
\hline$A * 68$ & 3 & 0.027 & 6 & 0.045 & - & 0.513 & & & & & \\
\hline$A * 74$ & 2 & 0.018 & 1 & 0.008 & - & 0.210 & & & & & \\
\hline HLA-B*07 & 2 & 0.018 & 16 & 0.121 & 9.472 & 0.002 & -2.133 & 7.237 & 0.007 & 0.188 & $0.225-0.560$ \\
\hline $\mathrm{B} * 08$ & 1 & 0.009 & 2 & 0.015 & - & 1.000 & & & & & \\
\hline B*13 & 0 & 0.000 & 12 & 0.091 & 10.708 & 0.001 & -8.088 & 0.227 & 0.630 & 0.000 & $0.000-8.383$ \\
\hline $\mathrm{B} * 14$ & 0 & 0.000 & 1 & 0.008 & - & 1.000 & & & & & \\
\hline $\mathrm{B} * 15$ & 30 & 0.268 & 14 & 0.106 & - & 0.001 & 1.206 & 9.659 & 0.002 & 3.341 & $1.561-7.148$ \\
\hline $\mathrm{B} * 35$ & 4 & 0.036 & 8 & 0.061 & 0.803 & 0.370 & & & & & \\
\hline $\mathrm{B} * 37$ & 2 & 0.018 & 0 & 0.000 & - & 0.210 & & & & & \\
\hline $\mathrm{B} * 39$ & 2 & 0.018 & 0 & 0.000 & - & 0.210 & & & & & \\
\hline$B * 40$ & 8 & 0.071 & 22 & 0.167 & 5.086 & 0.024 & -1.351 & 7.861 & 0.005 & 0.259 & $0.101-0.666$ \\
\hline$B * 41$ & 3 & 0.027 & 3 & 0.023 & - & 1.000 & & & & & \\
\hline$B * 44$ & 6 & 0.054 & 2 & 0.015 & - & 0.148 & 1.094 & 1.674 & 0.196 & 2.985 & $0.569-15.644$ \\
\hline$B * 45$ & 2 & 0.018 & 0 & 0.000 & - & 0.210 & & & & & \\
\hline$B * 46$ & 4 & 0.036 & 0 & 0.000 & - & 0.043 & 8.308 & 0.076 & 0.783 & 4057.79 & $0.000-2.130$ \\
\hline$B * 48$ & 5 & 0.045 & 4 & 0.030 & - & 0.736 & & & & & \\
\hline $\mathrm{B} * 50$ & 8 & 0.071 & 7 & 0.053 & 0.355 & 0.551 & & & & & \\
\hline $\mathrm{B} * 51$ & 8 & 0.071 & 20 & 0.152 & 3.826 & 0.050 & -0.697 & 2.029 & 0.154 & 0.498 & $0.191-1.300$ \\
\hline$B * 52$ & 3 & 0.027 & 4 & 0.030 & - & 1.000 & & & & & \\
\hline$B * 54$ & 6 & 0.054 & 2 & 0.015 & - & 0.148 & 1.552 & 2.953 & 0.086 & 4.719 & $0.804-27.700$ \\
\hline $\mathrm{B} * 55$ & 0 & 0.000 & 4 & 0.030 & - & 0.127 & -7.575 & 0.070 & 0.792 & 0.001 & $0.000-1.466$ \\
\hline$B * 57$ & 4 & 0.036 & 3 & 0.023 & - & 0.706 & & & & & \\
\hline $\mathrm{B} * 58$ & 14 & 0.125 & 8 & 0.061 & 3.063 & 0.080 & 0.814 & 2.711 & 0.100 & 2.257 & $0.856-5.951$ \\
\hline
\end{tabular}

$\mathrm{OR}=$ odds ratio $; 95 \% \mathrm{CI}=$ confidence interval at $95 \% ;(-)=$ indicates no $\chi^{2}$ value by the Fisher exact test. 
Sixteen alleles of HLA-A and 24 alleles of HLA-B were tested in Han children. The results showed that gene frequencies of HLA-A*26, HLA-B*35, and HLA-B*52 in patients were 7,11 and $9 \%$, respectively, which was significantly different than $10,4.7$ and $3.6 \%$ found in the control group $(\mathrm{P}=0.029, \mathrm{OR}=5.941,95 \% \mathrm{CI}=1.203-29.331, \mathrm{EF}=0.647 ; \mathrm{P}=0.040$, $\mathrm{OR}=3.041,95 \% \mathrm{CI}=1.050-8806, \mathrm{EF}=0.369 ; \mathrm{P}=0.038, \mathrm{OR}=3.202,95 \% \mathrm{CI}=1.065-9627$, $\mathrm{EF}=0.387$, respectively; Table 2), indicating that HLA-A*26, HLA-B*35, and HLA-B*52 were susceptible to HSP. There was no statistical significance between other alleles.

\begin{tabular}{|c|c|c|c|c|c|c|c|c|c|c|c|}
\hline \multirow{3}{*}{$\begin{array}{l}\text { HLA-A, } \\
\text {-B alleles }\end{array}$} & \multicolumn{4}{|c|}{ Univariate analysis } & \multirow[t]{3}{*}{$\chi^{2}$} & \multirow[t]{3}{*}{$P$} & \multicolumn{5}{|c|}{ Multivariate logistic regression } \\
\hline & \multicolumn{2}{|c|}{ Patients $(\mathrm{N}=100)$} & \multicolumn{2}{|c|}{ Control $(\mathrm{N}=192)$} & & & \multirow[t]{2}{*}{ B } & \multirow[t]{2}{*}{ Wald } & \multirow[t]{2}{*}{$\mathrm{P}$} & \multirow[t]{2}{*}{ OR } & \multirow[t]{2}{*}{$95 \% \mathrm{CI}$} \\
\hline & No. & Frequency & No. & Frequency & & & & & & & \\
\hline HLA-A*01 & 4 & 0.040 & 8 & 0.042 & - & 0.946 & & & & & \\
\hline $\mathrm{A} * 02$ & 37 & 0.370 & 65 & 0.339 & 0.286 & 0.593 & & & & & \\
\hline$A * 03$ & 5 & 0.050 & 9 & 0.047 & - & 1.000 & & & & & \\
\hline $\mathrm{A} * 11$ & 21 & 0.210 & 30 & 0.156 & 1.318 & 0.251 & & & & & \\
\hline$A * 23$ & 0 & 0.000 & 2 & 0.010 & - & 0.548 & & & & & \\
\hline $\mathrm{A} * 24$ & 13 & 0.130 & 40 & 0.208 & 2.716 & 0.099 & -0.595 & 2.881 & 0.090 & 0.552 & $0.278-1.096$ \\
\hline$A * 26$ & 7 & 0.070 & 2 & 0.010 & - & 0.009 & 1.782 & 4.783 & 0.029 & 5.941 & $1.203-29.331$ \\
\hline$A * 29$ & 0 & 0.000 & 1 & 0.005 & - & 1.000 & & & & & \\
\hline$A * 30$ & 1 & 0.010 & 8 & 0.042 & - & 0.172 & -1.548 & 2.095 & 0.148 & 0.213 & $0.026-1.730$ \\
\hline$A * 31$ & 4 & 0.040 & 6 & 0.031 & - & 0.740 & & & & & \\
\hline$A * 32$ & 2 & 0.020 & 4 & 0.021 & - & 1.000 & & & & & \\
\hline$A * 33$ & 3 & 0.030 & 13 & 0.068 & 1.805 & 0.179 & -0.937 & 2.037 & 0.153 & 0.392 & $0.108-1.419$ \\
\hline$A * 36$ & 1 & 0.010 & 0 & 0.000 & - & 0.342 & & & & & \\
\hline$A * 68$ & 1 & 0.010 & 1 & 0.005 & - & 1.000 & & & & & \\
\hline$A * 69$ & 0 & 0.000 & 1 & 0.005 & - & 1.000 & & & & & \\
\hline $\mathrm{A} * 74$ & 1 & 0.010 & 2 & 0.010 & - & 1.000 & & & & & \\
\hline HLA-B*07 & 0 & 0.000 & 4 & 0.021 & - & 0.303 & & & & & \\
\hline $\mathrm{B} * 08$ & 0 & 0.000 & 2 & 0.010 & - & 0.548 & & & & & \\
\hline $\mathrm{B} * 13$ & 6 & 0.060 & 18 & 0.094 & 0.993 & 0.319 & & & & & \\
\hline $\mathrm{B} * 15$ & 20 & 0.200 & 26 & 0.135 & 2.066 & 0.151 & 0.757 & 3.520 & 0.061 & 2.133 & $0.967-4705$ \\
\hline $\mathrm{B} * 27$ & 0 & 0.000 & 6 & 0.031 & - & 0.098 & -6.095 & 0.172 & 0.679 & 0.002 & $0.000-7.5243$ \\
\hline$B * 35$ & 11 & 0.110 & 9 & 0.047 & 4.107 & 0.043 & 1.112 & 4.205 & 0.040 & 3.041 & $1.050-8806$ \\
\hline$B * 37$ & 1 & 0.010 & 3 & 0.016 & - & 1.000 & & & & & \\
\hline$B * 38$ & 1 & 0.010 & 3 & 0.016 & - & 1.000 & & & & & \\
\hline$B * 39$ & 0 & 0.000 & 2 & 0.010 & - & 0.548 & & & & & \\
\hline$B * 40$ & 14 & 0.140 & 32 & 0.167 & 0.352 & 0.553 & & & & & \\
\hline$B * 44$ & 8 & 0.080 & 10 & 0.052 & 0.886 & 0.347 & & & & & \\
\hline$B * 46$ & 6 & 0.060 & 19 & 0.099 & 1.275 & 0.259 & & & & & \\
\hline$B * 48$ & 2 & 0.020 & 10 & 0.052 & - & 0.231 & & & & & \\
\hline$B * 49$ & 1 & 0.010 & 1 & 0.005 & - & 1.000 & & & & & \\
\hline$B * 50$ & 1 & 0.010 & 0 & 0.000 & - & 0.342 & & & & & \\
\hline $\mathrm{B} * 51$ & 11 & 0.110 & 18 & 0.094 & 0.194 & 0.660 & & & & & \\
\hline$B * 52$ & 9 & 0.090 & 7 & 0.036 & 3.639 & 0.056 & 1.164 & 4.293 & 0.038 & 3.202 & $1.065-9627$ \\
\hline$B * 54$ & 3 & 0.030 & 5 & 0.026 & - & 1.000 & & & & & \\
\hline$B * 55$ & 1 & 0.010 & 4 & 0.021 & - & 0.664 & & & & & \\
\hline$B * 57$ & 3 & 0.030 & 1 & 0.005 & - & 0.118 & 2.037 & 2.876 & 0.090 & 7.666 & $0.728-80705$ \\
\hline$B * 58$ & 1 & 0.010 & 8 & 0.042 & - & 0.172 & -0.908 & 0.680 & 0.410 & 0.403 & $0.047-3494$ \\
\hline$B * 59$ & 0 & 0.000 & 1 & 0.005 & - & 1.000 & & & & & \\
\hline$B * 67$ & 0 & 0.000 & 3 & 0.016 & - & 0.554 & & & & & \\
\hline $\mathrm{B} * 78$ & 1 & 0.010 & 0 & 0.000 & - & 0.342 & & & & & \\
\hline
\end{tabular}

$\mathrm{OR}=$ odds ratio $95 \% \mathrm{CI}=$ confidence interval at $95 \% ;(-)=$ indicates no $\chi^{2}$ value by the Fisher exact test. 
PCR-SBT was performed to further analyze susceptible loci found by PCR-SSO. Eight loci of HLA-A*11 and 4 loci of HLA-A*26 were HLA-A*1101 and HLA-A*2601, respectively; 7 of 10 loci of HLA-B*15 were HLA-B*1501, the rest were *1502, *1517 and $* 1518 ; 4$ of 7 loci of HLA-B*35 were HLA-B*3503, the rest were two $* 3501$ and one *3504 (Table 3).

Table 3. PCR-SBT result for susceptibility loci of HLA-A and -B in Mongolian and Han children with HenochSchöenlein purpura.

\begin{tabular}{lc}
\hline HLA-A* & HLA-B* \\
\hline 1101,2601 & 1501,3501 \\
1101,3101 & 1501,3503 \\
1101,2402 & 1502,5201 \\
1101,3303 & 1518,1302 \\
1101,2402 & 1501,4402 \\
1101,3303 & 1501,4001 \\
1101,1101 & 1501,5801 \\
2601,310102 & 1501,1517 \\
2601,0201 & 1501,5801 \\
2601,0206 & 3504,4601 \\
& 3503,4601 \\
& 3503,5701 \\
\hline
\end{tabular}

\section{Comparison of gene frequencies and manifestations between Mongolian and Han children with HSP}

Frequencies of HLA-A*26, HLA-B*35 and HLA-B*52 in Han patients were much more than those in Mongolian patients $(\mathrm{P}<0.05$; Table 4$)$, whereas the difference between frequencies of HLA-A*11, HLA-B*07, HLA-B*15, and HLA-B*40 in Mongolian and Han patients was not statistically significant $(\mathrm{P}>0.05$; Table 4$)$, indicating that the frequency distribution of HLA-A and B alleles between Mongolian and Han patients was different. HSP is a disease that involves multiple organs. The patients usually show purpura on limbs and have joint pain, gastrointestinal bleeding and purpuric nephritis. The incidence of gastrointestinal bleeding, angioneurotic edema and three damaged organs in Han patients was much higher than in Mongolian patients $(\mathrm{P}<0.05$; Table 5).

\begin{tabular}{|c|c|c|c|c|c|c|}
\hline \multirow[t]{2}{*}{ HLA-A, -B alleles } & \multicolumn{2}{|c|}{ Mongolian patients $(\mathrm{N}=112)$} & \multicolumn{2}{|c|}{ Han patients $(\mathrm{N}=100)$} & \multirow[t]{2}{*}{$\chi^{2}$} & \multirow[t]{2}{*}{$\mathrm{P}$} \\
\hline & No. & Frequency & No. & Frequency & & \\
\hline HLA-A*11 & 18 & 0.161 & 21 & 0.210 & 0.855 & 0.355 \\
\hline HLA-A $* 26$ & 0 & 0.000 & 7 & 0.070 & - & $0.005^{*}$ \\
\hline HLA-B*07 & 2 & 0.018 & 0 & 0.000 & - & 0.180 \\
\hline HLA-B*15 & 30 & 0.268 & 20 & 0.200 & 1.350 & 0.245 \\
\hline HLA-B*35 & 4 & 0.036 & 11 & 0.110 & 4.434 & $0.035^{*}$ \\
\hline HLA-B*40 & 8 & 0.071 & 14 & 0.140 & 2.671 & 0.102 \\
\hline HLA-B*52 & 3 & 0.027 & 9 & 0.090 & 3.953 & $0.047^{*}$ \\
\hline
\end{tabular}

*Indicates significant difference $(\mathrm{P}<0.05)$ by the Fisher exact test. 


\begin{tabular}{|c|c|c|c|c|c|c|}
\hline \multirow[t]{2}{*}{ Clinical characteristics } & \multicolumn{2}{|c|}{ Mongolian patients $(\mathrm{N}=56)$} & \multicolumn{2}{|c|}{ Han patients $(\mathrm{N}=50)$} & \multirow[t]{2}{*}{$\chi^{2}$} & \multirow[t]{2}{*}{$P$} \\
\hline & No. & Frequency & No. & Frequency & & \\
\hline Purpura on limbs & 0 & 0.000 & 3 & 0.060 & - & 0.102 \\
\hline Swelling and sore joints & 40 & 0.714 & 27 & 0.540 & 3.450 & 0.063 \\
\hline Purpuric nephritis & 16 & 0.286 & 19 & 0.380 & 1.062 & 0.303 \\
\hline Gastrointestinal bleeding & 4 & 0.071 & 11 & 0.220 & 4.800 & $0.028^{*}$ \\
\hline Electrocardiographic abnormality & 3 & 0.054 & 0 & 0.000 & - & 0.245 \\
\hline Swelling and sore testis & 0 & 0.000 & 1 & 0.020 & - & 0.472 \\
\hline Renal insufficiency & 0 & 0.000 & 1 & 0.020 & - & 0.472 \\
\hline Angioneurotic edema & 0 & 0.000 & 4 & 0.080 & - & $0.046^{*}$ \\
\hline Multiple organ damage & 14 & 0.250 & 17 & 0.340 & 1.034 & 0.309 \\
\hline Two damaged organs & 14 & 0.250 & 12 & 0.240 & 0.014 & 0.905 \\
\hline Three damaged organs & 0 & 0.000 & 5 & 0.100 & - & $0.021 *$ \\
\hline
\end{tabular}

*Indicates significant difference $(\mathrm{P}<0.05)$ by the Fisher exact test.

\section{DISCUSSION}

We studied the correlation of HLA-A and -B polymorphisms in Mongolian and Han children with HSP and found that the susceptible loci of Mongolian patients were HLA-A*11 and HLA-B*15; HLA-A*11 was also reported to be associated with HSP (Peru et al., 2008). The protecting genes were HLA-B*07 and HLA-B*40, and HLA-B*40 was also the protecting gene for hemorrhagic fever in nephrotic syndrome (Luo et al., 2008). The susceptibility loci of Han patients were HLA-A*26, HLA-B*35 and HLA-B*52; HLA-B*35 was also found to be a susceptibility locus for HSP (Amoli et al., 2002).

Comparison of gene frequencies between Mongolian and Han patients was performed, and gene frequencies found for HLA-A*26, HLA-B*35 and HLA-B*52 in Han patients were higher than in Mongolian patients; HLA-B*35 was considered to be a susceptibility gene for kidney damage in severe HSP (Amoli et al., 2002), while gene frequencies of HLA-A*11, HLA-B*07, HLA-B*15, and HLA-B*40 in Han patients were not significantly different compared with those in Mongolian patients, indicating that the gene frequency distribution of HLA-A and -B between Mongolian and Han patients was different. A comparison of manifestations between Mongolian and Han patients showed that the incidence of gastrointestinal bleeding, angioneurotic edema and three damaged organs in Han patients was higher than in Mongolian patients, indicating that the manifestations in Han patients with HSP were more severe than those for Mongolian patients.

Our result showed that the frequency distribution of HLA-A and -B alleles between Mongolian and Han patients was different, which may be one factor causing different manifestations of HSP in the two nationalities. The results of our study have important clinical implications for the medical staff in Inner Mongolia where both Mongolian and Han populations live, and provide reference to individualized treatment of HSP, estimation of prognosis and relapse.

\section{ACKNOWLEDGMENTS}

Research supported by the Scientific Research Funding from Inner Mongolia Medical College (\#NYZD-200303). 


\section{REFERENCES}

Amoli MM, Thomson W, Hajeer AH, Calvino MC, et al. (2002). HLA-B35 association with nephritis in Henoch-Schonlein purpura. J. Rheumatol. 29: 948-949.

Fan YL, Xia GQ, Cao LF, Jie J, et al. (2006). MHC-II (DQ) gene polymorphism and Henoch-Schöenlein purpura. Hei Long Jiang Med. J. 30: 94-96.

Flomenberg N, Baxter-Lowe LA, Confer D, Fernandez-Vina M, et al. (2004). Impact of HLA class I and class II highresolution matching on outcomes of unrelated donor bone marrow transplantation: HLA-C mismatching is associated with a strong adverse effect on transplantation outcome. Blood 104: 1923-1930.

Hughes EH, Collins RW, Kondeatis E, Wallace GR, et al. (2005). Associations of major histocompatibility complex class I chain-related molecule polymorphisms with Behcet's disease in Caucasian patients. Tissue Antigens 66: 195-199.

Kawasaki K, Komura H, Nakahara Y, Shiraishi M, et al. (2006). Factor XIII in Henoch-Schönlein purpura with isolated gastrointestinal symptoms. Pediatr. Int. 48: 413-415.

Liu Y, Sun LW, Li LH, Zhao YL, et al. (2008). Analysis of relevance between Henoch-Schöenlein purpura and HLADRB1 in children. Chin. J. Lab. Diagnosis 12: 1375-1377.

Luo JM, Sun WB, Huang XG, Li WH, et al. (2008). Correlation between the HLA-A, B alleles polymorphism and hemorrhagic fever with renal syndrome of Han nationality in Zunyi area. Chin. J. Microbiol. Immunol. 24: 430-435.

Ozen S, Ruperto N, Dillon MJ, Bagga A, et al. (2006). EULAR/PReS endorsed consensus criteria for the classification of childhood vasculitides. Ann. Rheum. Dis. 65: 936-941.

Peru H, Soylemezoglu O, Gonen S, Cetinyurek A, et al. (2008). HLA class 1 associations in Henoch Schönlein purpura: increased and decreased frequencies. Clin. Rheumatol. 27: 5-10.

Ren SM, Yang GL, Tong LH, Yu HL, et al. (2003). Association between clinical characteristics and HLA-DRB1 in Mongolian and Han children with Henoch-Schönlein purpura. Chin. J. Rheumatol. 7: 469-473.

Shen CM, Zhu BF and Li SB (2008). Analysis of gene polymorphism of HLA-A, B, DRB1 of Mongolian in Inner Mongolia. Hereditas 30: 164-168.

Shin JI, Park JM, Shin YH, Hwang DH, et al. (2006). Predictive factors for nephritis, relapse, and significant proteinuria in childhood Henoch-Schönlein purpura. Scand. J. Rheumatol. 35: 56-60.

Soylemezoglu O, Peru H, Gonen S, Cetinyurek A, et al. (2008a). CTLA-4 +49 A/G genotype and HLA-DRB1 polymorphisms in Turkish patients with Henoch-Schönlein purpura. Pediatr. Nephrol. 23: 1239-1244.

Soylemezoglu O, Peru H, Gonen S, Cetinyurek A, et al. (2008b). HLA-DRB1 alleles and Henoch-Schönlein purpura: susceptibility and severity of disease. J. Rheumatol. 35: 1165-1168.

Sun YP, Song CX, Li SL, Gao XJ, et al. (1984). Comparative study of Chinese human leucocyte antigen. Chin. J. Microbiol. Immunol. 4: 205-211.

Volz A, Boyle JM, Cann HM, Cottingham RW, et al. (1994). Report of the second international workshop on human chromosome 6. Genomics 21: 464-472.

Xu SB, Tao YF, Huang XQ, Chu ZT, et al. (2004). Polymorphism of HLA-DRB1 in Han population in Yunnan and comparison with 9 Han populations. Yi Chuan 26: 787-792.

Yan CX, Song YP, Lai SP, Lai JH, et al. (2002). Research on HLA-A polymorphism of Chinese Han and Uighur nationality by PCR-SSOP. J. Genet. Genomics 29: 384-389.

Yang GL, Ren SM, Shou QH, Su XL, et al. (2007). Susceptibility of HLA-A, B gene to Henoch-Schöenlein purpura in children. Chin. Clin. Med. 23: 850-853.

Zhang HB, Gao F, Kang LL and Li SB (2005). Polymorphism of HLA-A, B, DRB1 of Menba population in Tibet. Chin. J. Med. Genet. 22: 344-346. 